\title{
Early complications of interventional balloon catheterisation in infants and children
}

\author{
P Booth, A N Redington, E A Shinebourne, M L Rigby
}

\begin{abstract}
Interventional balloon catheterisation is now the recommended procedure for several congenital heart defects. The overall complication rate in the first 160 children (median age 3 years) to undergo balloon intervention (excluding balloon atrial septostomy) at the Brompton Hospital was $24 \%$ (14\% excluding haemorrhage and including three deaths (1.9\%)). Most complications were related to vascular problems at the site of cardiac catheterisation. Complications were more common in the younger patient, especially neonates, and also in procedures that were ultimately unsuccessful. Most complications were transient and usually had no long term effects. Improvements in equipment design and technical expertise may reduce morbidity from these procedures.
\end{abstract}

The immediate and intermediate results of balloon dilatation for isolated pulmonary valve stenosis and for recoarctation of the aorta compare favourably with the results of conventional surgery. ${ }^{1-3}$ The successful dilatation of aortic valve stenosis, ${ }^{4-6}$ of native coarctation of the aorta, ${ }^{7}$ of postoperative stenoses of veins or baffles, ${ }^{8}$ and of stenosed aortopulmonary shunts has been reported but the longer term outcome of these procedures is unknown.

It is surprising that there is only one report of the acute complications of interventional catheterisation in adults and children. ${ }^{9}$ The present study reviews the complications in children and represents our initial experience in the first 160 patients.

Department of Paediatric Cardiology, Royal Brompton and National Heart Hospital, London P Booth

A N Redington

E A Shinebourne M L Rigby

Correspondence to Dr M L Rigby, Department of Paediatric Cardiology, Royal Brompton and National Heart Hospital, Fulham Road, London SW3 6HP.

Accepted for publication 9 October 1990 in two. Infants undergoing balloon atrial tostomy are not included. This study is confined to the 160 children who underwent

\section{Patients and methods}

Peen January 1984 and June 1989,1795 infants and children under the age of 16 year cardiac catheterisation at the who underwent interventional procedures, consisting of balloon dilatation $(n=160)$, embolisation of pulmonary-systemic collaterals $(n=10)$, and blade atrial septostomy balloon dilatation. Figure 1 shows the relative frequency of these procedures as a proportion of all cardiac catheterisations by year. Age at catheterisation ranged from 3 days to 16 years (median 3 years). There were 10 neonates $(6.3 \%), 16$ infants $(10 \%)$, and 134 children $(83.7 \%)$. Seven patients had repeat procedures. One hundred and nineteen $(75 \%)$ procedures were considered to be successful on clinical, angiographic, and haemodynamic criteria. A procedure was considered unsuccessful if: $(a)$ it was technically impossible; $(b)$ there was less than a $50 \%$ reduction in the peak systolic gradient across a stenosis; $(c)$ the patient required conventional surgery after balloon intervention. Otherwise the intervention was regarded as an early success. Table 1 lists the procedures undertaken and their individual success rate. All the procedures were performed by or under the supervision of one of four operators.

All balloon dilatation procedures were performed by standard techniques. In general, direct percutaneous insertion of the balloon catheter was used, except in some neonates undergoing balloon dilatation of aortic coarctation or critical pulmonary stenosis, when the balloon catheter was inserted via a valved introducer. Balloon size was selected according to previously published criteria. ${ }^{10-12}$ The balloon diameter for dilatation of post-Mustard baffle obstruction and dilatation of the

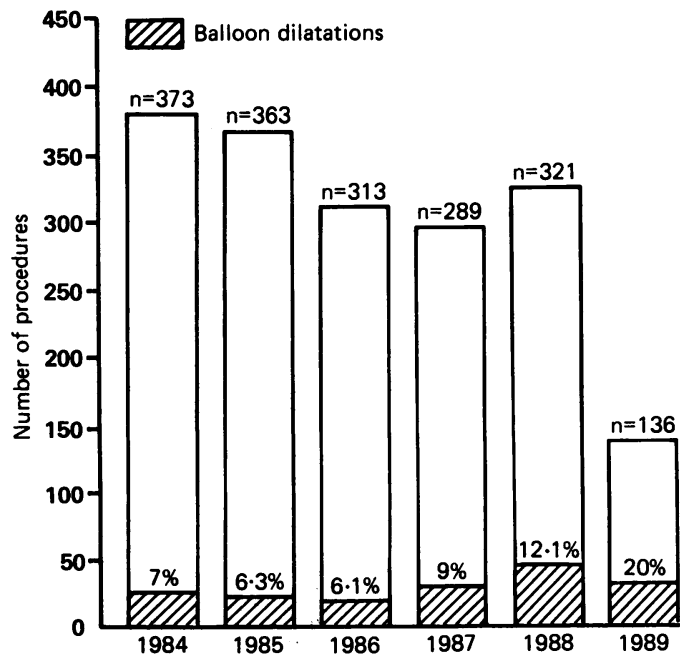

Figure 1 Proportion of cardiac catheterisations that were balloon dilatations. $n=$ the total number of paediatric patients undergoing cardiac catheterisation. 
Table 1 Procedures undertaken and their individual success rate

\begin{tabular}{lll}
\hline Procedure & Total & Successful $(\boldsymbol{n}(\%))$ \\
\hline Dilatation of pulmonary valve stenosis & 81 & $70(86)$ \\
Dilatation of aortic valve stenosis & 12 & $5(42)$ \\
Dilatation of aortic coarctation: & 34 & $28(82)$ \\
Native coarctation & 16 & $15(93)$ \\
Recoarctation & 18 & $13(72)$ \\
Dilatation of stenoses after Mustard's operation & 12 & $10(83)$ \\
Miscellaneous: & 21 & $6(29)$ \\
Dilatation of stenoses after arterial switch operation & & 9 \\
Dilatation of pulmonary artery stenosis & 4 \\
Dilatation of stenosis after truncus repair & & 2 \\
Dilatation of stenoses after DORV and VSD repair & & 1 \\
Dilatation of stenosis after PA correction & & 1 \\
Dilatation of stenosis after correction of TOF & & 1 \\
Dilatation of mitral valve stenosis & & 1 \\
Dilatation of supravalvar pulmonary stenosis (Noonan's) & & \\
\hline
\end{tabular}

DORV, double outlet right ventricle; PA, pulmonary atresia; TOF, tetralogy of Fallot; VSD, ventricular septal defect.
Table 3 Minor complications after balloon dilatation procedures

\begin{tabular}{lc}
\hline Complication & No \\
\hline Transient loss of pulse & 10 \\
Haemorrhage and transfusion & 7 \\
Damage to axillary artery & 1 \\
Venous occlusion & 1 \\
Erb's palsy & 1 \\
Pulmonary artery puncture, no haemorrhage & 1 \\
\hline
\end{tabular}

There were three deaths $(1.9 \%)$ (tables 2 and 3). Seven patients had two complications and one patient had three. The complication rates for individual procedures ranged from $7 \%$ for dilatation of the pulmonary valve to $53 \%$ for coarctation aortoplasty (fig 2 ). The complication rate was especially high $(69 \%)$ for aortoplasty of native coarctation.

Complications were more common in the younger patients. The rate was $70 \%$ for neonates, $44 \%$ for infants, and $19 \%$ for children ( $p<0.001, \chi^{2}$ test for trend). The median age of the patients in whom complications developed was 24 months; the median age of the patients who had no complications was 43 months. The difference between the median ages was significant ( $p=0 \cdot 009$, Mann-Whitney $U$ test). The $95 \%$ confidence interval for the difference in medians was $(4.0$ to 27.8$)$. Complications developed in $18(15 \%)$ of the 119 patients who had successful procedures and in $21(51 \%)$ of the 41 patients who had an unsuccessful procedure $\left(p<0.001, \chi^{2}\right.$ test with Yates's correction).

During the period of the study the incidence of complications increased from $17.5 \%$ in the first 30 months to $28 \%$ in the second, though the rate for dilatation of the pulmonary valve fell.

SPECIFIC PROCEDURES AND THEIR COMPLICATIONS

Dilatation of the pulmonary valve

The success rate $(86 \%)$ was the highest of all the procedures and the complication rate $(7 \%)$ the lowest. There was one death (in a 5 day old infant) and in a 10 day old infant with a severely dysplastic pulmonary valve Staphylococcus bradycardia, and occasional ventricula extrasystoles during balloon inflation but these were not regarded as complications.

\section{Results}

There were 48 complications in 39 patients (24\%), of which 27 were major and 21 minor.

Table 2 Major complications after balloon dilatation procedures

\begin{tabular}{ll}
\hline Complication & No \\
\hline Haemorrhage and hypotension & 10 \\
Femoral artery occlusion & 3 \\
Ventricular fibrillation & $2(2$ died $)$ \\
Hemiparesis/hemiplegia & 2 \\
Cardiac arrest & 1 \\
Perforation of right ventricular outflow tract & 1 (died) \\
Complete heart block & 1 \\
Aortic regurgitation & 1 \\
Lower limb ischaemia & 1 \\
Ruptured catheter & 1 \\
Aortic dissection & 1 \\
Aortic aneurysm & 1 \\
Air in left atrial appendage & 1 \\
Septicaemia and valvar endocarditis & 1 \\
\hline
\end{tabular}

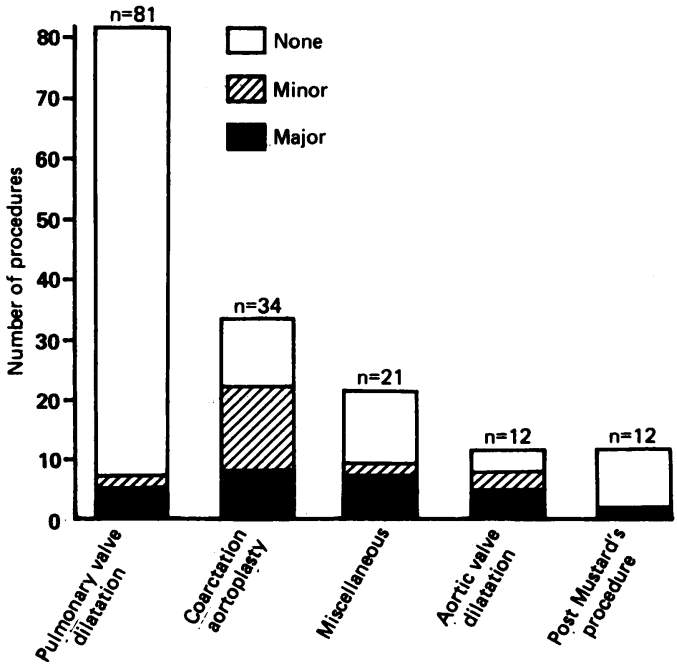

Figure 2 Complication rate by procedure. $n=$ the number of patients in each group. 
Figure 3 Success and failure rate of balloon intervention per year of procedure. $n=$ the total number of balloon dilatations performed on paediatric patients.

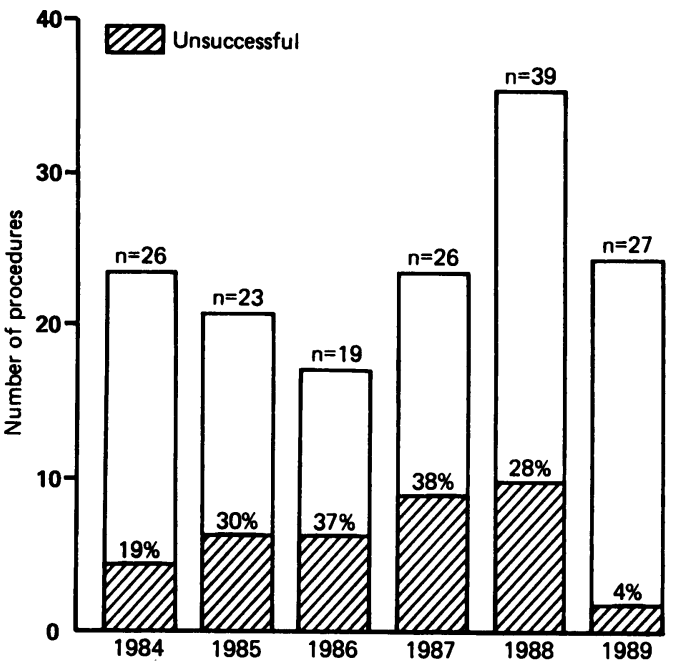

aureus septicaemia developed after an unsuccessful procedure. At operation, two weeks later, endocarditis of the pulmonary valve and the arterial duct was noted together with a small pulmonary artery tear and a subadventitial haematoma. The child made an uneventful recovery after an open valvotomy and removal of the infected tissue. A 10 month old infant had a successful procedure but developed transient complete heart block necessitating admission to the intensive care unit. Three children had problems with bleeding at the site of cardiac catheterisation; two become hypotensive and required admission to the intensive care unit.

\section{Dilatation of the aortic valve}

The success rate of $42 \%$ was poor and the complication rate of $50 \%$ was high. Only one of the patients with complications had a successful procedure. There was one death, from late ventricular fibrillation. Two patients, aged 11 and 14 years, had persistent loss of pulse despite treatment with anticoagulant and antifibrinolytic agents. They both required surgical exploration of the femoral arteries; simple thrombectomy was performed in one, but in the other a saphenous patch was used. A six year old girl developed axillary artery thrombosis which resolved after five days of anticoagulation treatment. This same patient developed aortic incompetence and later underwent successful open valvotomy with repair of the valve. Finally, there were two patients with bleeding from the site of cardiac catheterisation. One required admission to the intensive care unit; the second also developed transient loss of pulse.

\section{Coarctation aortoplasty}

Thirty four patients underwent balloon aortoplasty. This group had a good initial success rate $(82 \%)$ but the highest complication rate $(53 \%)$. Eighteen of the procedures were performed in patients with recoarctation (14 after subclavian flap angioplasty, three after end-toend anastomosis, and one after previous balloon aortoplasty). Primary balloon aortoplasty in 15 of 16 patients, including seven neonates, was initially successful. There were minor complications in 14 patients and major complications in eight. Four infants and an 18 month old child were admitted to the intensive care unit because of haemorrhage and hypotension or loss of pulse or both. All had successful procedures with no long term sequelae. One two week old infant had a successful aortoplasty but a small aneurysm was noted immediately. One three year old boy was noted to have a cold, pulseless right leg. Despite appropriate treatment intermittent claudication developed; magnetic resonance imaging showed stenosis of the right femoral artery. A three day old infant was admitted to the intensive care unit after unsuccessful balloon aortoplasty which was complicated by major blood loss. At operation, three days later, there was an aortic dissection of the coarctation and isthmus necessitating end-to-end repair. The minor complications involved nine patients with transient loss of pulse requiring anticoagulant treatment and four with bleeding from the site of cardiac catheterisation requiring blood transfusion but without haemodynamic disturbance.

\section{Baffle obstruction after Mustard's operation}

There were 12 procedures in 11 patients who had developed baffle obstruction. Eight underwent dilatation of the inferior limb of the baffle, three dilatation of the inferior and superior limb, and one the superior limb alone. The success rate of the procedures was high $(83 \%)$ and the complication rate low (16\%). One patient underwent two procedures for dilatation initially of the inferior limb and later of both limbs of the baffle. He developed a transient right hemiparesis on both occasions.

\section{Miscellaneous}

Table 1 lists procedures undertaken. The success rate was low (29\%) and the complication rate was $33 \%$. There was one death from ventricular fibrillation. A two year old child with Williams's syndrome and severe supravalvar aortic stenosis and peripheral pulmonary artery stenosis had repeated episodes of asystole after induction of general anaesthesia and during attempted dilatation of her pulmonary artery stenoses. She has recovered fully. Circumferential rupture of the balloon occurred in a 16 year old girl undergoing dilatation of a homograft conduit; it proved impossible to remove the catheter percutaneously and she required surgical exploration. Other complications included major haemorrhage with hypotension in one patient, transient loss of foot pulse in another, and venous thrombosis requiring anticoagulation in a third. All made a complete recovery. Finally, attempted dilatation of a supravalvar mitral ring in a two year old was unsuccessful and was complicated by minor haemorrhage. More importantly, fluoroscopy showed air in her left atrial appendage. She subsequently underwent surgical removal of the supravalvar ring with no long term sequelae. 
DEATHS

There were three deaths. A five day old infant with severe aortic and pulmonary valve stenosis died from cardiac tamponade. A five month old infant who had undergone an arterial switch operation died 24 hours after unsuccessful attempted dilatation of critical stenosis of right and left pulmonary artery stenosis. Finally, spontaneous ventricular fibrillation developed two hours after balloon dilatation of the aortic valve in a six month old infant who had undergone open aortic valvotomy as a neonate.

\section{Discussion}

Complications developed in $39(24 \%)$ of the first 160 infants and children undergoing balloon dilatation procedures. Permanent sequelae from these complications were uncommon, though there were three deaths $(1.9 \%)$.

Unlike Fellows et al, ${ }^{9}$ we included haemorrhage from the catheter site that required elective blood transfusion as a complication of balloon interventional procedures. If these 17 patients are excluded, the type and frequency $(14 \%)$ of complications in our study are remarkably similar to those reported in Fellows et al's review of adults and children. What is clear from both studies is that complications of balloon interventional catheterisation increase in frequency in the younger patient, especially neonates. We also showed that complications were more frequent in patients who had an unsuccessful procedure (fig 3), presumably because these were more prolonged and technically difficult. Vascular problems associated with site of cardiac catheterisation (haemorrhage, arterial occlusion etc) accounted for 33 of the complications. It seems reasonable to conclude that the frequency of these complications may fall with further miniaturisation of equipment.

Our success and low complication rates after dilatation of the pulmonary valve accord with those reported by other workers. ${ }^{12}{ }^{13}$ The complication rate $(53 \%)$ for coarctation aortoplasty was the highest of all procedures. This was balanced by its high initial success rates of $82 \%$ overall and $94 \%$ for native coarctations. Fourteen were minor complications-that is, transient loss of the foot pulse or haemorrhage from the catheter site. There was a preponderance of neonates and infants in this group, and like Fellows et $a l^{9}$ we have shown an increased complication rate in these patients. It is clear that an arterial approach and younger age are significantly associated with both minor and major complications. Indeed, the complication rate rose from $17.5 \%$ over the first 30 months of the study to $28 \%$ over the past 30 months. This almost certainly reflects the increasing number of neonates and infants being treated, the trend towards primary balloon aortoplasty for coarctation, and the relative reduction in frequency of dilatation of the pulmonary valve.

Several workers have reported deaths after balloon dilatation, especially for aortic stenosis, aortic coarctation, and pulmonary artery stenosis. ${ }^{14-16}$ In general, the overall mortality is comparable to that of the surgical alternative. Deaths reported after balloon intervention have been due to ventricular fibrillation, vessel rupture, or occlusion of a critical obstruction. The deaths in our study were caused by perforation of the right ventricular outflow tract in one and later ventricular fibrillation in two patients. The exact cause of late arrhythmias is unknown, but it is now our policy to monitor the electrocardiogram continuously for 24 hours after most procedures.

We described a retrospective review of balloon interventional techniques in infants and children. Overall the early complication rate was high but the frequency of complications likely to lead to long term sequelae was low. With continued improvement in equipment and operator technique, many of these complications may be avoidable.

1 Tynan M, Baker EJ, Rohmer J, et al. Percutaneous balloon pulmonary valvuloplasty. Br Heart J 1985;53:520-4.

2 Sullivan ID, Robinson PJ, Macartney FJ, et al. Percutaneous balloon valvuloplasty for pulmonary valve stenosis in infants and children. Br Heart $J$ 1985;54:435-41.

3 Lock JE, Bass JL, Amplatz K, et al. Balloon dilatation angioplasty of coarctation in infants and children. Circulation 1983;68:109-16.

4 Saul JP, Keane JF, Fellows KE, et al. Balloon dilatation angioplasty of postoperative aortic obstructions. $\mathrm{Am} \mathrm{J}$ Cardiol 1987;59:943-8.

5 Rupprath G, Neuhaus KL. Percutaneous balloon valvuloplasty for aortic valve stenosis in infancy. Am J Cardiol plasty for aortic

6 Wren C, Sullivan I, Bull C, Deanfield J. Percutaneous balloon dilatation of aortic valve stenosis in neonates and infants. Br Heart $J$ 1987;58:608-12.

7 Wren C, Peart J, Bain H, Hunter S. Balloon dilatation of unoperated aortic coarctation: immediate results and one year follow up. Br Heart $J$ 1987;58:369-73.

8 Lock JE, Bass JL, Castaneda-Zuniga W, et al. Dilation angioplasty of congenital or operative narrowings of venous channels. Circulation 1984;70:457-64.

9 Fellows KE, Radtke W, Keane JF, et al. Acute complications of catheter therapy for congenital heart disease. Am J Cardiol 1987;60:679-83.

10 Radtke W, Keane JF, Fellows KE, et al. Percutaneous balloon valvotomy of congenital pulmonary stenosis using oversized balloons. J Am Coll Cardiol 1986;8:909-15.

11 Miller GAH. Balloon valvuloplasty and angioplasty in congenital heart disease. Br Heart J 1986;54:285-9.

12 Lababidi Z, Wu J, Walls JT. Percutaneous balloon aortic valvuloplasty: results in 23 patients. Am J Cardiol 1984, 53:194-7.

13 Rao PS, Fawzy ME, Solynar L, et al. Long terms results of balloon pulmonary valvuloplasty. Am Heart J 1988 115:1291-6.

4 Ring JC, Bass JL, Marvin W, et al. Management of congenital stenosis of a branch pulmonary artery with balloon dilatation angioplasty; report of 52 procedures. $J$ Thorac Cardiovasc Surg 1985;90:35-44.

15 Finley JP, Beaulieu RG, Nanton MA, Roy DL. Balloon catheter dilatation of coarctation of the aorta in young infants. Br Heart J 1983;50:411-5.

16 Kasten-Sportes CH, Peichaud JF, Sidi D, et al. Percutaneous balloon valvuloplasty in neonates with critical aortic stenosis. J Am Coll Cardiol 1989;5:1101-5. 